Ergonomics, and we have done the work focused on this perception of the existing risks.

Objective It is understood ergonomics as adaptation of work to man, application of scientific knowledge necessary to design tools, machines and devices that can be used with maximum comfort, safety and effectiveness (FALZON, 2007). The purpose of the work is not different from those principles that the author puts forward.

The proposal, in addition to providing a work environment that minimises problems related to wrist pain, understands the cognitive processes present in the athletes' daily lives.

Analysis methodology For methodology we will use the points predicted in the AET: demand, analysis of the task, analysis of the activity, diagnosis, proposals and implementations. Methods by observing and elaborating questions pertinent to what you are encountering. Application of ergonomic tools and installation of Mouse Metre software, measuring the intensity of clicks per second on the mouse (direct button and left button), mouse movement on the desktop, clicks on the keyboard. A questionnaire with 6 players was carried out. 3 perform gym and 1 practice race.

Conclusion The study aims to contribute to the community of electronic sports and ergonomics, because it is a relatively new area for the field of work, it is interesting that there is knowledge about the aspects related to the ergonomics involved in the activity of the athletes. The analysis is based on ergonomics as a whole (cognitive, organisational and physical) - and it was evidenced that for many hours sitting, in front of computer with inadequate posture (even by the body's need to modify positions for its comfort), keyboard use Intensely, and stare at the screen to perform the avatar commands correctly, with reflexes and at the right time.

It is noticed that almost $60 \%$ of the day of them they spend playing (they are seated during 13 hours of the day),

They perform wrist movements and very intense hands (both by typing and by clicking) and identify pains in the shoulders, forearms, wrists and cervical, most common on the side that use the mouse for the most part (dominant member). Players with their own chair feel less discomfort in the body, players with more complaints of pain are those who do not have support in the arm chair.

The cognitive part they discuss game strategy, in-game communication, decision-making to achieve in-game goals are in direct interactivity with the game interface (map, skills, goal time, gold conquered); Players may know part of the habilities of the 137 players available in the game - where each champion/player has an average of 5 skills - in a total of 500 skills, but there are no reports of player complaints about this seemingly idiosyncratic use of cognitive skills.

\section{THE DEVELOPMENT OF SLEEP AND SAFETY DECISION MAKING AMONG LESS EXPERIENCED/'YOUNG' TRUCK DRIVERS: A QUALITATIVE DESCRIPTIVE STUDY}

Karen Heaton*, Rachael Mumbower, Gwendolyn Childs. University of Alabama at Birmingham School of Nursing, Birmingham, Alabama, USA

10.1136/oemed-2018-ICOHabstracts. 1720

American truck drivers are at risk for sleep deprivation and subsequent increased risk for sleep - related motor vehicle crash. In spite of their significant risks, little is known about how truck drivers make sleep and safety decisions. The purpose of this study was to describe influences on sleep and safety-related decision-making among a group of long-haul truck drivers.

The qualitative descriptive study focused on a purposive sample $(n=10)$ recruited from truckstops, by word of mouth, and flyers posted at locations commonly visited by truck drivers. Semi-structured interviews were conducted with participants. All interviews were audio-recorded and transcribed verbatim prior to analysis. A cyclic approach to coding was used to develop and revise the code book. The process was repeated until themes were generated. Trustworthiness and credibility were enhanced by using reflexivity, an audit trail, and interpretive convergence.

Four general themes emerged from driver descriptions of influences of health-related decision making:

- individual driver characteristics

- key events,

- relationships with others, and

- company-level factors.

From analysis of the interviews, it was clear that individual driver characteristics, key events, personal and professional relationships, and company-level factors all influenced health and safety decision-making of this sample of long-haul truck drivers. An important finding was that drivers new to the profession ('young drivers') evolved over time as they gained experience to self-advocate for their sleep and safety - related health needs; and thus, made different sleep decisions.

Factors influencing health and safety decision-making must be considered when providing care and teaching to truck drivers. Involving family members and important others to assist in motivating truck drivers may be an effective strategy to positively influence health and safety decision-making. It will be especially important to target interventions to the less experienced ('younger') drivers. Findings from this study may be used to inform the development of educational materials and other interventions to positively influence truck driver health and safety decision-making, which could lead to a healthier transportation workforce and safer highways for the public.

\section{SELF-CERTIFIED SICKNESS ABSENCE AMONG YOUNG MUNICIPAL EMPLOYEES - CHANGES FROM 2002 TO 2016 AND OCCUPATIONAL CLASS DIFFERENCES}

H Sumanen*, O Pietiläinen*, M Mänty*. Department of Public Health, University of Helsinki, Finland

\subsection{6/oemed-2018-ICOHabstracts. 1721}

Introduction Young employees have self-certified 1-3 day sickness absence (SA) more often than their older counterparts, but the burden of self-certified SA and its occupational class differences have only little previous evidence. We examined the changes in self-certified SA among young employees from 2002 to 2016 and the magnitude of occupational class differences during that period.

Methods All 18-34 year-old employees of the City of Helsinki, Finland were included (2002-2016, $\mathrm{n}=\sim 11725$ per year). Employer's personnel and SA registers were used. Occupational class was categorised to four groups: managers and professional, semi-professionals, routine non-manuals and manual workers. Changes in the self-certified SA spells and days 
from 2002 to 2016 were analysed with joinpoint regression and the magnitudes of occupational class differences were estimated with the relative index of inequality (RII).

Results Most of the trends first increased and turned to decrease in 2007/2010. Managers and professionals had the least amount of self-certified SA, but steadily increasing trends were observed among men. Self-certified SA followed only partially the typical socioeconomic gradient, as routine nonmanuals had the highest levels of SA. The magnitude of occupational class differences in self-certified SA was stable during the study period only among women. Self-certified SA and occupational class differences have increased in recent years among men in the lower occupational classes.

Conclusion Socioeconomic differences exist in self-certified SA among young employees, but gradient is only partial. Overall, high amounts of self-certified SA especially in the lower occupational classes are in need for further studies and preventive measures.

\section{BEATING BURNOUT, BEING KIND - OAK}

${ }^{1}$ Zakiah Amir*, ${ }^{2}$ Anna McHugh, ${ }^{3}$ Lynda Sisson. ${ }^{1}$ Faculty of Occupational Medicine, Royal College of Physicians of Ireland, Dublin, Ireland; 'Letterkenny University Hospital, Letterkenny, Ireland; ${ }^{3}$ Workplace Health and Wellbeing Unit, Health Service Executive, Dublin, Ireland

\subsection{6/oemed-2018-ICOHabstracts. 1722}

Introduction There is increasing evidence of burnout among healthcare workers (HCW). Workers engagement is one solution to burnout with positive outcomes towards patient care and work satisfaction. Simple, low key positive activities have been shown to make differences to people in a pressurised environment. Our intervention aims to establish whether acts of kindness at work can affect workers engagement.

Methods Occasional Acts of Kindness (OAK) was a pilot intervention programme trialled in a large tertiary hospital in December 2016. All HCWs were invited to attend the 2 hours session when participants take a break from work in a friendly atmosphere, sit for a while, engage with one another and ask colleagues about how they were coping with work and life. The effectiveness of this intervention was evaluated using a validated staff engagement questionnaire, Utrecht Work Engagement Scale. Participants were also encouraged to leave their own comments regarding the intervention.

Result $65 \mathrm{HCWs}$ of varying grades and departments participated. $97 \%$ of participants agree that the intervention boosts collegiality and strengthens relationships at work, 90\% agree it would make them more likely to take the initiative to help a struggling colleague, $80 \%$ agree it boosts their energy at work, $83 \%$ agree it increases their mental resilience at work, $90 \%$ agree it enhances their enthusiasm at work, $87 \%$ agree it helps them persevere even if things are not going well, 63\% agree it helps them continue working even for long period, $84 \%$ agree it helps instil a sense of pride in workplace and 93\% agree it boosts overall morale at work. Their additional comments regarding the intervention were also cohesively positive.

Discussion Our intervention proved that acts of kindness at work have multitudes positive effects on workers and work. A culture of kindness is one solution to the growing issue of burnout among HCW.
478

DOCPASS: A TOOL TO ASSESS READINESS FOR WORK IN SURGEONS AND ANAESTHETISTS TO IMPROVE AND ENSURE SAFETY OF PATIENTS

BM de Niet*, MHW Frings-Dresen, JK Sluiter. Academic Medical Centre, Coronel Institute of Occupational Health, Amsterdam Public Health research institute, Amsterdam, The Netherlands

10.1136/oemed-2018-ICOHabstracts. 1723

Introduction To protect patient safety in the operating room it is important to create awareness among surgeons and anaesthetists on their own work readiness and its influence on their performance. The purpose of the study was to design a tool (DOCpass), study its feasibility in daily operating room practice and redesign it based on suggestions made by future end users.

Methods The content of the DOCpass prototype was selected on the basis of aspects of health and work that can influence performance as was found in literature. A suitable platform was subsequently chosen to meet pre-defined requirements such as ease of use and accessibility of the tool. To determine the feasibility in the operating room practice and collect points of improvement for redesign, post-task walkthroughs were organised with surgeons and anaesthetists at a university medical centre in the Netherlands.

Result DOCpass was developed as a webpage in JavaScript and HTML which makes the tool accessible from local hospital computers or mobile devices (e.g. mobile phone, tablet). It screens for personal aspects (e.g. fatigue and mood states) and work-related aspects (e.g. shift and sleeping time duration) that have been found to affect performance and patient safety in practice. A total of 13 improvement points were suggested by future end users and the prototype was adjusted according to these. The improvements concerned the content of the introduction, the relevance of screening methods and applicability of feedback.

Conclusion DOCpass assesses and provides feedback on work readiness in colour coding through digital screening of work and personal health aspects. Participating surgeons and anaesthetists in the feasibility study reported that the tool is potentially useful in the operating room were the content to be improved. Feedback that is provided should be easy to act upon and could in this way add practical value to work.

\section{DEVELOPMENT OF AN INTERVENTION FOR NURSES' SUSTAINABLE EMPLOYABILITY: A FOCUS GROUP STUDY}

${ }^{1}$ LAM Brouwers*, ${ }^{2}$ JA Engels, ${ }^{2}$ YF Heerkens, ${ }^{3} \mathrm{AJ}$ Van der Beek. ${ }^{1} \mathrm{PHD}$ student, HAN University of Applied Sciences, Nijmegen, The Netherlands; ${ }^{2}$ Professor of HAN University of Applied Sciences, Nijmegen, The Netherlands; ${ }^{3}$ Professor, Head of Department of Public and Occupational Health, VU University Medical Centre, Amsterdam, The Netherlands

\subsection{6/oemed-2018-ICOHabstracts. 1724}

Introduction In today's Western world, people have to work longer before they can retire and the working population is ageing. In healthcare, due to an increase in complexity, severity and extent of the demand for health care, it is of great importance to invest in retention of nurses, who are considered particularly vulnerable in staying employable.

A structured dialogue between employee and supervisor is seen as promising opportunity to improve sustainable employability of nurses and the corresponding required working behaviour. In order to accomplish so-called 'joint ownership', 